\title{
A deformation-processed Al-matrix/Ca-nanofilamentary composite with low density, high strength, and high conductivity
}

\author{
Liang Tian ${ }^{\mathrm{a}, \mathrm{e}}$, Alan Russell ${ }^{\mathrm{b}, \mathrm{c}}$, Trevor Riedemann $^{\mathrm{c}}$, Soeren Mueller ${ }^{\mathrm{d}}$, Iver Anderson ${ }^{\mathrm{b}, \mathrm{c}}$ \\ a. Department of Materials Science and Engineering, University of Michigan, Ann Arbor, MI, 48109, USA \\ b. Department of Materials Science and Engineering, Iowa State University, Ames, IA, 50011, USA \\ c. Ames Laboratory of the U.S. Department of Energy, Ames, IA 50011, USA \\ d. Technische Universität Berlin, Gustav-Meyer-Allee 25, 13355 Berlin. GE \\ e. Corresponding author: E-mail: lilangt @ umich.edu, Tel: +1 515-509-0857, Address: 2018 Gerstacker Bldg, 2200 Bonisteel, \\ Ann Arbor, MI, 48109, USA.
}

\begin{abstract}
Light, strong materials with high conductivity are desired for many applications such as power transmission conductors, fly-by-wire systems, and downhole power feeds. However, it is difficult to obtain both high strength and high conductivity simultaneously in a material. In this study, an Al/Ca (20 vol.\%) nanofilamentary metal-metal composite was produced by powder metallurgy and severe plastic deformation. Fine Ca metal powders $(\sim 200 \mu \mathrm{m})$ were produced by centrifugal atomization, mixed with pure $\mathrm{Al}$ powder, and deformed by warm extrusion, swaging, and wire drawing to a true strain of 12.9. The Ca powder particles became fine $\mathrm{Ca}$ nanofilaments that reinforce the composite substantially by interface strengthening. The conductivity of the composite is slightly lower than the rule-of-mixtures prediction due to minor quantities of impurity inclusions. The elevated temperature performance of this composite was also evaluated by differential scanning calorimetry and resistivity measurements.
\end{abstract}

Keywords: Metal matrix composite (MMCs); Powder processing; Severe plastic deformation; Strength; Electrical resistivity/conductivity

\section{Introduction}


Low density, high strength, and high electrical conductivity are desirable material properties for many applications such as electric power transmission cables, fly-by-wire control systems, and downhole power feeds [1]. However, it is challenging to produce a material with both high strength and high electrical conductivity. Conventional strengthening methods such as strain hardening, second-phase hardening, precipitate hardening, or solid solution hardening significantly decrease conductivity. A type of composite called deformation processed metalmetal composites (DMMCs) has been found to exceed the rule-of-mixtures strength prediction and also deliver an electrical conductivity nearly equal to the rule-of-mixtures prediction [2]. DMMCs are produced by (1) powder metallurgy or (2) solidification of a liquid solution of two elements that are mutually insoluble in the solid state, followed by severe plastic deformation [3]. The two metal phases used for composite production must be highly ductile to sustain deformation true strain as high as 16 without fracturing. The second (minority) phase deforms into fine filaments that reinforce the composite by interface strengthening, which strengthen the metal by blocking dislocation glide at the interfaces. DMMCs are essentially nano-scale bundles of two pure metals whose unique microstructure provides minimal electron scattering effect (along the filament direction) from solute impurities, interfaces, grain boundaries, or dislocations [4].

Though many DMMC systems have been studied in the past few decades [2], none possess densities and electrical conductivities close to those of pure $\mathrm{Al}$. Al/Ca DMMCs were invented [5] to produce a light, highly conductive, high-strength composite conductor. Both $\mathrm{Al}$ and $\mathrm{Ca}$ are low-density, low-cost, and highly ductile fcc metals. They are the fourth and fifth most conductive metallic elements (after the three Group 11 elements: $\mathrm{Cu}, \mathrm{Ag}$, and $\mathrm{Au}$ ). In $\mathrm{Al} / \mathrm{Ca} \mathrm{DMMCs}$, the highly reactive Ca filaments are embedded inside the $\mathrm{Al}$ matrix, which 
isolates the $\mathrm{Ca}$ from environmental oxygen and moisture, giving the composite excellent corrosion resistance. The first-generation $\mathrm{Al} / \mathrm{Ca}(9 \mathrm{vol} . \%)$ composite was produced to prove this concept and to study the microstructure-property relationships [6]. However, the Ca metal used in producing that first-generation composite was commercially available $\mathrm{Ca}$ granules with average diameter around $1.2 \mathrm{~mm}$. After a deformation true strain of 13.7, these granules were deformed into $2 \mu \mathrm{m}$ filaments, which were still too coarse to provide the large strength increases seen in previous investigations on $\mathrm{Al} / \mathrm{Mg}$ [7] and $\mathrm{Al} / \mathrm{Ti}$ [8]. The investigations on $\mathrm{Al} / \mathrm{Mg}$ and Al/Ti DMMCs demonstrated low densities and high strengths, but Mg's conductivity is mediocre and Ti's is poor, rendering unexceptional conductivities.

In this study, we used Ca metal powders with average diameter around $200 \mu \mathrm{m}$ to produce second-generation composite, $\mathrm{Al} / \mathrm{Ca}$ (20 vol. \%). It was anticipated that the finer $\mathrm{Ca}$ filaments and larger Ca volume fraction would produce higher strength. Since no commercial vendors produce fine $\mathrm{Ca}$ metal powders, Ca powders used in this experiment were produced by a centrifugal atomization device designed and fabricated at the Ames Laboratory of the U.S D.O.E [9]. The processing, microstructure, and strength/conductivity relationship in $\mathrm{Al} / \mathrm{Ca}$ (20 vol. \%) composite were studied, and the results are reported here.

\section{Experimental Procedure}

High-purity (99.99 \%) Al powders produced by the Ames Laboratory gas atomization reaction synthesis (GARS) process $(45-106 \mu \mathrm{m})$ were mixed with high-purity $(99.5 \%)$ fine $\mathrm{Ca}$ metal powder $(106-212 \mu \mathrm{m})$ produced by the aforementioned centrifugal atomization system [10]. Mixed powders (80 vol. \%, $157 \mathrm{~g} \mathrm{Al}$ and 20 vol. \%, $22.4 \mathrm{~g} \mathrm{Ca}$ ) were die pressed into cylindrical powder compacts (diameter $75 \mathrm{~mm}$, height $25.4 \mathrm{~mm}$ ) under a pressure of 40.6 MPa. The powder 
compacts had a density of $65 \%$, which matched the compressibility curve for gas atomized $\mathrm{Al}$ powder [11]. The powder compacts were loaded into a pure $\mathrm{Al}$ (1100-H14) extrusion can (inside diameter $78 \mathrm{~mm}$, outside diameter $90 \mathrm{~mm}$ and internal length $196.8 \mathrm{~mm}$ ) and outgassed in vacuo at a pressure of $2.7 \times 10^{-5} \mathrm{~Pa}$ to remove gasses and moisture adsorbed on the powder particles, prior to e-beam welding the container's end cap. The extrusion can loaded with $\mathrm{Al} / \mathrm{Ca}$ powder compacts were extruded at the Extrusion Research \& Development Center at the Technical University of Berlin, Germany, to produce $\mathrm{Al} / \mathrm{Ca}$ (20 vol. \%) composite rod. The indirect extrusions were done using a container with an inner diameter of $95 \mathrm{~mm}$ and an extrusion die with a die orifice of $27.3 \mathrm{~mm}$. For the billets, an initial temperature of $285^{\circ} \mathrm{C}$ was chosen, which was thought to be hot enough to activate a sufficient number of slip systems to promote easy deformation but cool enough to avoid formation of Al-Ca intermetallics. Extrusion was done with an extrusion force of $1.9 \mathrm{MN}$ in the stationary condition at a ram speed of $1.5 \mathrm{~mm} / \mathrm{s}$. The metal billet diameter reduced from $89 \mathrm{~mm}$ to $27.3 \mathrm{~mm}$, which gives an extrusion ratio of 10.6. The deformation true strain $\eta$ of the specimen is calculated by $\eta=2 \operatorname{In}\left(d_{0} / d_{f}\right)$, where $d_{0}$ and $d_{f}$ are the initial and final specimen diameters, respectively. The as-extruded composite specimen had a deformation true strain of 1.93 , after accounting for its $35 \%$ porosity and void space in the container. The extrusion process transforms spherical Ca metal particles into co-axial filaments.

The $\mathrm{Al}$ sleeve from the pure $\mathrm{Al}$ extrusion can was removed from the $\mathrm{Al} / \mathrm{Ca}$ composite rod with a lathe. Further deformation at room temperature by swaging was conducted. The composite rod was reduced to $2.95 \mathrm{~mm}$ diameter wire (deformation true strain 6.39). The middle section of the $2.95 \mathrm{~mm}$ composite wire was further swaged at room temperature to $1 \mathrm{~mm}$ diameter (deformation true strain 8.52). Wire drawing was used from this point to achieve a deformation true strain of 12.9 and wire diameter of $0.112 \mathrm{~mm}$. At a true strain of 12.9 , the 
$\mathrm{Al} / \mathrm{Ca}$ composite was expected to contain Ca filaments with average diameter around $200 \mathrm{~nm}$, which should be sufficiently fine to induce a substantial strengthening effect, while maintaining high electrical conductivity [4].

Microstructure, tensile strength, and electrical conductivity were measured at various deformation true strain levels. Microstructures were studied by field emission-scanning electron microscopy with a Quanta 250 instrument. Lower true-strain specimens were prepared for metallography by polishing on $\mathrm{SiC}$ grinding paper with hexane to 1200 grit; further polishing was performed using $1 \mu \mathrm{m}$ glycol-diamond polishing fluid. (Conventional polishing fluids like MetaDi or organic solvents cannot be used because they contain trace amounts of water that attack the Ca filaments.) Focused-ion-beam cutting followed directly by SEM imaging was employed for the $\eta=12.9$ sample to eliminate polishing and exposure to air.

Tensile tests were done with an Instron 3367 system using an elongation rate of 2 $\mathrm{mm} / \mathrm{min}$. (average of three independent tests) of the $\mathrm{Al} / \mathrm{Ca}(20 \mathrm{vol} . \%)$ sample at true strain levels lower than 8.5. A Zwick/Roell Model Z 2.5 tensile tester was used for testing samples with deformation true strains 8.5 and above; while the $\eta=12.9$ samples were measured at Psylotech's facility on their $\mu \mathrm{TS}$, an "under-microscope" universal test system. Sample length was measured between grip fronts with a caliper. Specimen diameter was measured using pixel measurement from the $5 \times 2$ optics of the microscope. An average of several diameter data points along the length of the sample was used for the area calculation. The elongation ramp rate is about $240 \mu \mathrm{m} / \mathrm{sec}$.

Differential scanning calorimetry (DSC) tests were conducted on a Netzsch STA449 F1 DSC system with a heating rate of $5{ }^{\circ} \mathrm{C} / \mathrm{min}$ on $\mathrm{Al} / \mathrm{Ca}$ samples with various deformation true strain levels to evaluate the microstructure evolution at elevated temperature. 
Electrical resistivity/conductivity data were measured by the four-point probe method with a Keithley 224 constant current source $(100 \mathrm{~mA})$ and a Keithley 614 electrometer for both as-deformed and annealed $1 \mathrm{~mm} \mathrm{Al} / \mathrm{Ca}$ wire samples to study the effects of annealing time and temperature on the microstructure. Similar processing procedures of $\mathrm{Al} / \mathrm{Ca}$ wire were performed on pure $\mathrm{Al}$ powders of the same size range to get pure $\mathrm{Al}$ powder compacts (64\% dense) to be deformed into $1 \mathrm{~mm}$ pure $\mathrm{Al}$ wire (deformation true strain 8.52), which serve as a control specimen in resistivity measurements.

\section{Results and Discussions}

\subsection{Microstructure characterization of $\mathrm{Al} / \mathrm{Ca}(20 \mathrm{vol} . \%)$ composite}

Fig.1 shows the as-deformed microstructure of $\mathrm{Al} / \mathrm{Ca}(20 \mathrm{vol} . \%)$ composite at different deformation true strains. The light gray Ca filaments adopted a ribbon-shaped morphology instead of the expected cylindrical shape. According to the classic composite morphology theory $[2,12]$, in a fcc matrix DMMC, a bcc metal filament tends to develop a $\langle 110\rangle$ fiber texture parallel to the deformation axis, which leads to a plain strain deformation mode that would form a ribbon-like curling filamentary morphology. In contrast, fcc filaments tend to deform axisymmetrically to develop a cylindrical filament morphology due to the larger number of slip planes available in a textured fcc matrix.

It is possible that the ribbon-shaped Ca filaments, apparent in Fig. 1(b) and (c), result from the temporary temperature rise and large shear stress present during extrusion, causing a temporary crystal structure transformation from fcc $\mathrm{Ca}$ to bcc $\mathrm{Ca}$. It should be noted that the equilibrium fcc-bcc transformation in pure Ca occurs at 728K [13] 
Figure 1. Back-scattered electron SEM (scanning electron microscopy) micrographs of AlCa (20 vol.\%) composite: (a) longitudinal cross section at deformation true strain $\eta$ 6.38, (b) transverse cross section at $\eta 8.52$, (c) transverse cross section at $\eta 12.91$. The light-gray phase is $\mathrm{Ca}$; the dark-gray phase is $\mathrm{Al}$. Grain structure contrast is visible within the $\mathrm{Al}$ in (c). The vertical bands in this micrograph are "curtaining" artifacts from the focused-ion beam cutting.

The Ca filament thickness can be measured from the SEM micrographs, and are summarized in Table 1. It is readily apparent that the filament thickness decreased sharply as deformation true strain increased. An exponential dependence of filament thickness on deformation true strain was found to be $120.3 \exp (-0.499 \eta)(\mu \mathrm{m})$. This thickness dependence matched well with the ideal Hall-Petch thickness dependence $\mathrm{d}_{0} \exp (-0.5 \eta)(\mu \mathrm{m})$, where $\mathrm{d}_{0}$ is between 100 and $200 \mu \mathrm{m}$.

Table 1. Calcium filament thicknesses at different deformation true strains measured from the SEM micrographs in Fig. 1.

\subsection{Strength of $\mathrm{Al} / \mathrm{Ca}(20 \mathrm{vol} . \%)$ composite}

Fig. 2 shows the tensile testing stress-strain curves for $\mathrm{Al} / \mathrm{Ca}$ tensile specimens at various deformation true strains. The tensile strengths at various deformation true strain levels are summarized in Table 2.

Figure 2. Tensile tests of Al/Ca (20 vol.\%) composite at various deformation true strain levels.

Table 2. The ultimate tensile strength of $\mathrm{Al} / \mathrm{Ca}$ (20 vol.\%) composites at various deformation true strains. 
Fig. 3 shows the experimental relationship between deformation true strain and tensile strength of $\mathrm{Al} / \mathrm{Ca}$ composite wires and the fitting result by a Hall-Petch barrier model, which gave the strength as $81.53+157.2 / \operatorname{sqr}[120.3 \exp (-0.499 \eta)] \mathrm{MPa}$. As these data show, as the deformation true strain increases, the tensile strength increases exponentially for this $\mathrm{Al} / \mathrm{Ca}$ (20 vol. \%) composite. This suggests that the strengthening effect of $\mathrm{Al} / \mathrm{Ca}$ composite is largely contributed by interface strengthening that is much less effective at low deformation true strain levels due to the small interface area associated with the coarse Ca filament size. The interface area increases exponentially with increasing deformation true strain due to the smaller $\mathrm{Ca}$ filament size. At high deformation true strains, the Ca filament thickness was reduced to the submicron regime (Fig. 1c), which generates a large amount of interface area to strengthen the composite by acting as barriers to dislocation motion [3].

Figure 3. Tensile strength of $\mathrm{Al}-20 \mathrm{vol} . \% \mathrm{Ca}$ composite as a function of deformation true strain. The experimental data are fitted by a Hall-Petch barrier model, which is the solid curve. The ultimate strengths of four commonly used commercial conductors are shown for comparison. (ACAR=Aluminum Conductor Aluminum Alloy Reinforced; ACSR=Aluminum Conductor Steel Reinforced; AAAC=All Aluminum Alloy Conductor; $\mathrm{ACCC} / \mathrm{TW}=$ Aluminum Conductor Composite Core with Trapezoidal Wire cross section.)

Fracture surface of tensile tested sample at deformation true strain 12.9 are exhibited in Fig. 4. The fracture surface shows the feature of ductile fracture mode. The fracture surface of tensile tested samples at lower deformation true strain shows similar features. This suggests that the $\mathrm{Al} / \mathrm{Ca}$ composite wire possesses some ductility even at this high true strain level of deformation processing.

Figure 4. The fracture surface of tensile tested sample at deformation true strain of 12.9. 


\subsection{Differential scanning calorimetry measurements on Al/Ca (20 vol.\%) composite}

Differential scanning calorimetry (DSC) tests were performed in $\mathrm{Ar}$ atmosphere on $\mathrm{Al} / \mathrm{Ca}$ (20 vol. \%) composite to explore possible microstructure transformations at elevated temperature. Previous investigation on $\mathrm{Al} / \mathrm{Ca}(9$ vol. \%) composite [6] suggested that there are two exothermic reactions occurring during DSC testing. One is the formation of $\mathrm{Al}_{4} \mathrm{Ca}$ at $225^{\circ} \mathrm{C}$ and the other is the formation of $\mathrm{Al}_{2} \mathrm{Ca}$ at $275^{\circ} \mathrm{C}$ [6]. The formation of these intermetallic compounds would alter the performance of the $\mathrm{Al} / \mathrm{Ca}$ composite conductor at the mildly elevated temperatures that occur during routine conductor service and the substantially elevated temperatures that can occur during emergency overloading. Formation of the intermetallics is irreversible, and they persist even when the metal is subsequently cooled to room temperature. Therefore, studying these reactions for $\mathrm{Al} / \mathrm{Ca}(20 \mathrm{vol} . \%)$ composite at elevated temperature is important. Figure 5 shows the DSC curves for various $\mathrm{Al} / \mathrm{Ca}$ (20 vol. \%) composite samples at different deformation true strains. It is clear that intermetallic formation begins at a higher temperature for as-extruded samples with low deformation true strain than for samples deformed to high true strain. This is probably attributable to the fact that the micron- and submicron-size Ca filaments in highly deformed samples possess a greater driving force for the reaction due to curvature-driven atomic mixing from the Gibbs-Thompson effect [14]. Also, in the as-extruded $(\eta=1.93)$ sample, there appears to be one exotherm with an onset temperature of $335.4^{\circ} \mathrm{C}$. In contrast, in the two as-swaged samples $(\eta=6.38$ and 8.52), two exothermic events have been observed. The first event is presumably due to the $\mathrm{Al}_{4} \mathrm{Ca}$ formation, since the $\mathrm{Al}_{4} \mathrm{Ca}$ formation has a less negative enthalpy of formation $\left[\Delta \mathrm{H}_{\mathrm{f}}\left(\mathrm{Al}_{4} \mathrm{Ca}\right.\right.$, solid, $\left.\left.298 \mathrm{~K}\right)=-43.9 \pm 4.2 \mathrm{~kJ} / \mathrm{mol}\right]$ than that of $\mathrm{Al}_{2} \mathrm{Ca}\left[\Delta \mathrm{H}_{\mathrm{f}}\left(\mathrm{Al}_{2} \mathrm{Ca}\right.\right.$, solid, $\left.\left.298 \mathrm{~K}\right)=-73.2 \pm 4.2 \mathrm{~kJ} / \mathrm{mol}\right]$ [15], which causes the first 
exothermic peak to be small. The binary phase diagram for the Al-Ca system is shown in Figure 6 for reference. In addition, $\mathrm{Al}_{4} \mathrm{Ca}$ is less stable $\left[\Delta \mathrm{G}_{\mathrm{f}}\left(\mathrm{Al}_{4} \mathrm{Ca}\right.\right.$, solid, $\left.800 \mathrm{~K}\right)=-17800 \pm 140$ $\mathrm{J} / \mathrm{mol}]$ and will decompose into $\mathrm{Al}_{2} \mathrm{Ca}\left[\Delta \mathrm{G}_{\mathrm{f}}\left(\mathrm{Al}_{2} \mathrm{Ca}\right.\right.$, solid, $\left.\left.800 \mathrm{~K}\right)=-28500 \pm 300 \mathrm{~J} / \mathrm{mol}\right]$. The second event presumably results from the formation of $\mathrm{Al}_{2} \mathrm{Ca}$, which is the most stable intermetallic compound in the Al-Ca binary system with a melting temperature of $1081^{\circ} \mathrm{C}$, as seen in Fig. 6.

Figure 5. The DSC curves for Al/Ca (20 vol. \%) composite samples at different deformation true strains under argon atmosphere. The as-extruded $27.3 \mathrm{~mm}$ sample has deformation true strain of 1.93. The as-swaged $3 \mathrm{~mm}$ sample has deformation true strain 6.38 . The as-swaged $1 \mathrm{~mm}$ sample has deformation true strain 8.52 .

Figure 6. Phase diagram for the Al-Ca system. ASM Diagram No. 1600365, Okamoto (2003) [13].

\subsection{Electrical resistivity of $\mathrm{Al} / \mathrm{Ca}(20$ vol. \%) composite and pure $\mathrm{Al}$}

The electrical resistivity of as-deformed $1 \mathrm{~mm} \mathrm{Al} / \mathrm{Ca}$ composite wire and $1 \mathrm{~mm}$ pure $\mathrm{Al}$ wire (deformation true strain $=8.52$ ) were determined by four-point probe resistivity measurement. The electrical resistivity of $1 \mathrm{~mm} \mathrm{Al} / \mathrm{Ca}(20$ vol. \%) composite wire was measured to be $0.0305 \mu \Omega \cdot \mathrm{m}$, while the measured resistivity of $1 \mathrm{~mm}$ pure Al wire was $0.0283 \mu \Omega \cdot \mathrm{m}$. The resistivity of the composite is $3.4 \%$ higher than the predicted $0.0295 \mu \Omega \cdot \mathrm{m}$ by the inverse rule of mixtures. This difference may result from crystal defects such as powder particle oxide layer debris inclusions and/or from an increased dislocation density. Increased dislocations could be from statistically stored dislocations (SSDs) and/or geometrically necessary dislocations (GNDs), both of which result from the strain hardening and increased interface area. Since the pure Al specimen was observed to dynamically recrystallize during deformation, the resistivity 
measurements on annealed pure $\mathrm{Al}$ wire suggest that the resistivity originating from increased dislocation density by strain hardening is negligible. In the $\mathrm{Al} / \mathrm{Ca}$ composite wire, the GNDs are generated to accommodate the $\mathrm{Al} / \mathrm{Ca}$ interface area, which could be another contribution to resistivity when the $\mathrm{Ca}$ filaments are submicron in size. However, in the $1 \mathrm{~mm} \mathrm{Al} / \mathrm{Ca}$ composite wire, the Ca filament size is close to $2 \mu \mathrm{m}$, which is too coarse to generate a strong interface scattering effect. It is also possible that the elevated resistivity values for $\mathrm{Al} / \mathrm{Ca}$ composite wires result from deformation-induced chemical mixing to form localized solid solutions that increase the resistivity.

The resistivity of $\mathrm{Al} / \mathrm{Ca}(20 \mathrm{vol} . \%)$ composite at deformation true strain 12.9 was predicted by the model proposed in Ref [4]. The mean free path of $\mathrm{Al}$ and $\mathrm{Ca}$ was estimated to be 14 and $27 \mathrm{~nm}$ according to Ref [16]. From the microstructure image of composite wire with deformation true strain 12.9 shown in Fig.1, the average Ca ribbon shaped filament thickness is about $50 \mathrm{~nm}$ and the average $\mathrm{Al}$ matrix phase thickness (filament spacing) is about $500 \mathrm{~nm}$. Based on Ref [4] eq.(2) for ribbon shaped filaments and eq.(4) for matrix, the modified Al matrix resistivity and $\mathrm{Ca}$ filament resistivity considering the interface scattering is $0.0286 \mu \Omega \bullet \mathrm{m}$ and $0.0396 \mu \Omega \bullet \mathrm{m}$ with a reasonable estimating choice of $\mathrm{p}=0.5$. The resistivity of $\mathrm{Al} / \mathrm{Ca}(20 \mathrm{vol} . \%)$ composite at deformation true strain 12.9 is predicted to be $0.0303 \mu \Omega \bullet \mathrm{m}$ by modified inverse rule of mixtures. The conductivity $33.02(\mu \Omega \bullet \mathrm{m})^{-1}$ is higher than most current commonly used conductors in Ref [1].

The electrical resistivity values of the $\mathrm{Al} / \mathrm{Ca}$ composite wire and pure $\mathrm{Al}$ wire annealed at elevated temperature have been measured to evaluate the effect of possible high-temperature annealing in electrical transmission service that may alter both the microstructure and the resistivity of $\mathrm{Al} / \mathrm{Ca}$ composite wire. Tables 3 and 4 present the resistivity of $1 \mathrm{~mm} \mathrm{Al} / \mathrm{Ca}$ 
composite wire and $1 \mathrm{~mm}$ pure $\mathrm{Al}$ wire annealed at $300^{\circ} \mathrm{C}$ for various times (data plotted in Fig. 7). From Table 4 , we can see that the annealing of $1 \mathrm{~mm}$ pure $\mathrm{Al}$ wire $(\eta=8.5)$ at $300{ }^{\circ} \mathrm{C}$ has no significant effect on its resistivity. This suggested that the resistivity contribution from increased dislocation density of pure $\mathrm{Al}$ wire due to deformation is negligible, and that the pure $\mathrm{Al}$ surface is quite resistant to oxidation to maintain its low resistivity. The surface of $\mathrm{Al} / \mathrm{Ca}$ composite rapidly becomes essentially pure Al following exposure to air, so the composite wire should be resistant to oxidation as well.

Table 3. The electrical resistivities of $1 \mathrm{~mm} \mathrm{Al/Ca} \mathrm{(20} \mathrm{vol.} \mathrm{\% )} \mathrm{composite} \mathrm{wire} \mathrm{(deformation} \mathrm{true}$ strain 8.5) annealed at $300^{\circ} \mathrm{C}$ for different times.

Table 4. The electrical resistivities of $1 \mathrm{~mm}$ pure $\mathrm{Al}$ wire (deformation true strain 8.5 ) annealed at $300^{\circ} \mathrm{C}$ for different times.

Figure.7 Summary of the electrical resistivities of $1 \mathrm{~mm}$ dia. $\mathrm{Al} / \mathrm{Ca}(20 \mathrm{vol} . \%)$ composite wire as a function of annealing time at $300^{\circ} \mathrm{C}, 200^{\circ} \mathrm{C}$, and $125^{\circ} \mathrm{C}$ (data from Tables 3,5 , and 6 respectively), along with electrical resistivity data from $1 \mathrm{~mm}$ dia. pure Al wire (data from Table 4) annealed at $300^{\circ} \mathrm{C}$.

From Table 3, we can see that the resistivity of Al/Ca (20 vol. \%) composite increases after annealing at $300^{\circ} \mathrm{C}$ for $600 \mathrm{~s}$. This resistivity increase is most likely attributed to intermetallic formation. Recall that $\mathrm{Al}_{2} \mathrm{Ca}$ was observed to form at $275{ }^{\circ} \mathrm{C}$ in $\mathrm{Al} / \mathrm{Ca}(9 \mathrm{vol} . \%)$ composite $(\eta=8.55)[6]$, and the DSC test on $1 \mathrm{~mm} \mathrm{Al} / \mathrm{Ca}(20$ vol. \%) composite wire $(\eta=8.5)$ suggested that $\mathrm{Al}_{2} \mathrm{Ca}$ formed at $258.9{ }^{\circ} \mathrm{C}$ (see Fig. 5). To verify this, the resistivity of arc-melted pure $\mathrm{Al}_{2} \mathrm{Ca}$ specimens (confirmed by X-ray diffraction) has been measured to be $0.1115 \mu \Omega \cdot \mathrm{m}$, 
roughly 4 times that of pure Al. If we assume that all Ca filaments had been fully converted to $\mathrm{Al}_{2} \mathrm{Ca}$ by annealing at $300^{\circ} \mathrm{C}$, the volume fraction for $\mathrm{Al}$ and $\mathrm{Al}_{2} \mathrm{Ca}$ would be $40 \%$ and $60 \%$, respectively. By using an inverse rule of mixtures, the resistivity of $\mathrm{Al} / \mathrm{Al}_{2} \mathrm{Ca}(60 \mathrm{vol} . \%)$ composite is calculated to be $0.0513 \mu \Omega \cdot \mathrm{m}$, which closely matches the measured resistivity value of $0.0515 \mu \Omega \cdot \mathrm{m}$. This suggests that the initial resistivity increase due to annealing at $300^{\circ} \mathrm{C}$ for only 10 min is caused by the complete transformation of $\mathrm{Ca}$ filaments into $\mathrm{Al}_{2} \mathrm{Ca}$.

To further understand the elevated temperature performance of $\mathrm{Al} / \mathrm{Ca}$ composite wire, the resistivities were measured after annealing at $200^{\circ} \mathrm{C}$ and $125^{\circ} \mathrm{C}$ for various lengths of time, as shown in Tables 5 and 6 (data plotted in Fig.7). Table 5 clearly shows that the resistivity increased after 10 mins annealing and then stabilized for another 25 mins. This could be due to the formation of intermetallic compound $\mathrm{Al}_{4} \mathrm{Ca}$, as one can see from the DSC curve in Fig. 4. Based on a simple inverse rule of mixtures (48 vol.\% $\mathrm{Al}$ and $52 \mathrm{vol} . \% \mathrm{Al}_{4} \mathrm{Ca}$ ) and the stable resistivity of $\mathrm{Al} / \mathrm{Ca}$ wire at $25 \mathrm{mins}$, a resistivity of $0.0517 \mu \Omega \cdot \mathrm{m}$ was derived for $\mathrm{Al}_{4} \mathrm{Ca}$. This is about half the value for $\mathrm{Al}_{2} \mathrm{Ca}$ and twice the value of $\mathrm{Al}$. After that, the resistivity of $\mathrm{Al} / \mathrm{Ca}$ wire began to increase at a slow, nearly constant rate. This could be due to the slow decomposition of $\mathrm{Al}_{4} \mathrm{Ca}$ to $\mathrm{Al}_{2} \mathrm{Ca}$ at relatively low temperature $\left(200{ }^{\circ} \mathrm{C}\right)$, since $\mathrm{Al}_{4} \mathrm{Ca}$ is the less stable of the two compounds, as the DSC curves showed. Table 6 for annealing of the wire at $125^{\circ} \mathrm{C}$ shows that the resistivity increased gradually up to 140 mins. This could result from the formation of $\mathrm{Al}_{4} \mathrm{Ca}$ at $125^{\circ} \mathrm{C}$, but at a much slower rate than at $200{ }^{\circ} \mathrm{C}$. If so, the $\mathrm{Al}_{4} \mathrm{Ca}$ persisted for about 6 hours, then began to decompose into $\mathrm{Al}_{2} \mathrm{Ca}$, as suggested by the slow resistivity rise in Fig. 7 . It is worthwhile to mention that the 0 min resistivity result in Table 5 is somewhat different from those in Table 3 and 6, probably due to some extra surface contamination during the resistivity sample preparation of Table 5. However, these surface impurities should not affect the 
resistivity increase during the isothermal annealing. To summarize, the formation of $\mathrm{Al}_{4} \mathrm{Ca}$ and $\mathrm{Al}_{2} \mathrm{Ca}$ seems to occur at all three temperatures with $\mathrm{Al}_{2} \mathrm{Ca}$ being the more stable phase. As one would expect, the rate of formation and decomposition varies greatly with temperature.

Table 5. The electrical resistivities of $1 \mathrm{~mm} \mathrm{Al/Ca} \mathrm{(20} \mathrm{vol.} \mathrm{\% )} \mathrm{composite} \mathrm{wire}$ (deformation true strain 8.5 ) annealed at $200{ }^{\circ} \mathrm{C}$ for different times.

Table 6. The electrical resistivities of $1 \mathrm{~mm} \mathrm{Al/Ca} \mathrm{(20} \mathrm{vol.} \mathrm{\% )} \mathrm{composite} \mathrm{wire}$ (deformation true strain 8.5 ) annealed at $125{ }^{\circ} \mathrm{C}$ for different times.

From the equilibrium $\mathrm{Al}-\mathrm{Ca}$ phase diagram [13], it is known that $\mathrm{Al}$ and $\mathrm{Ca}$ have essentially no mutual solid solubility at thermodynamic equilibrium. $\mathrm{Al}_{2} \mathrm{Ca}$ formation may require a pre-existing $\mathrm{Al} / \mathrm{Ca}$ solution, as suggested by the phase diagram and the fact that the pure $\mathrm{Al}_{2} \mathrm{Ca}$ sample was obtained by arc melting to get a liquid solution of $\mathrm{Al}$ and $\mathrm{Ca}$. Therefore, there is a possibility that the contact between pure solid $\mathrm{Al}$ and pure solid $\mathrm{Ca}$ would not form $\mathrm{Al}_{2} \mathrm{Ca}$ at the interface because $\mathrm{Al}$ and $\mathrm{Ca}$ have no mutual solubility and would not form $\mathrm{Al} / \mathrm{Ca}$ solid solution. In addition, the DSC results in Fig. 5 for the $\eta=8.5$ sample also suggests that the formation of the $\mathrm{Al}_{2} \mathrm{Ca}$ was preceded by the formation of the $\mathrm{Al}_{4} \mathrm{Ca}$ phase, presumably at the true $\mathrm{Al} / \mathrm{Ca}$ interface where there is only slight penetration of the $\mathrm{Ca}$ atoms into the $\mathrm{Al}$ lattice, which make the $\mathrm{Al}_{4} \mathrm{Ca}$ phase kinetically favored by this decreased interatomic mixing even though the driving force for formation of the $\mathrm{Al}_{2} \mathrm{Ca}$ phase is higher.

However, there is a phenomenon called deformation-induced chemical mixing that has been widely observed in heavily co-deformed metallic composites [17]. This phenomenon can cause the complete dissolution of a minority filament phase into the matrix phase. Several 
mechanisms of deformation-induced mixing have been suggested. One such mechanism is dislocation shuffling, which suggests that the shear transfer by multiple slip systems of two phases across the heterophase interface can lead to massive chemical mixing by shearing tiny embedded one-phase particles into another phase. These tiny particles would dissolve into their surrounding phase through the curvature-driven, dissolution-Gibbs-Thomson effect due to the small size of particles, though the two phases are mutually insoluble under thermodynamic equilibrium.

This mechanism would seem to be applicable to some degree for the fcc $\mathrm{Al}$ and fcc $\mathrm{Ca}$ phases, since both share the same multiple slip systems. Table 3 presents one corroborating observation supporting this hypothesis because it shows that the resistivity after $10 \mathrm{~min}$. of annealing can be explained by the inverse rule of mixtures of pure $\mathrm{Al}(40 \mathrm{vol} . \%)$ and pure $\mathrm{Al}_{2} \mathrm{Ca}$ (60 vol.\%). This suggests occurrence of the eventual intermixing of $\mathrm{Ca}$ to form $\mathrm{Al} / \mathrm{Ca}$ solid solution that eventually transforms into $\mathrm{Al}_{2} \mathrm{Ca}$ during annealing. The DSC results in Fig. 5 also show that annealing above about $260^{\circ} \mathrm{C}$ should also complete transformation to $\mathrm{Al}_{2} \mathrm{Ca}$ at the $\mathrm{Al} / \mathrm{Ca}$ interface. If $\mathrm{Al}_{4} \mathrm{Ca}$ is formed by the initial reaction of $\mathrm{Al}$ and $\mathrm{Ca}$ at the interface, the diffusion barrier effect of $\mathrm{Al}_{4} \mathrm{Ca}$ at the interface for transport of $\mathrm{Al}$ into $\mathrm{Ca}$ or $\mathrm{Ca}$ into $\mathrm{Al}$ should slow the kinetics of $\mathrm{Al}_{2} \mathrm{Ca}$ formation substantially. This diffusion barrier effect does seem to be operating in this system since a higher temperature was needed to complete the transformation to $\mathrm{Al}_{2} \mathrm{Ca}$, although it is complete within $10 \mathrm{~min}$. of annealing at $300^{\circ} \mathrm{C}$. This annealing temperature is higher than the onset of $\mathrm{Al}_{2} \mathrm{Ca}$ formation at $260^{\circ} \mathrm{C}$ that was observed on continuous heating in Fig. 5.

The observation (see Fig. 5) that a temperature as low as $177^{\circ} \mathrm{C}$ is sufficient to start transforming the $\mathrm{Al} / \mathrm{Ca}$ composite microstructure into an $\mathrm{Al} /$ intermetallic composite at even a 
modest deformation true strain of 8.5 has several implications. First, there might have to be a limit specified on the possible Joule heating that the conductor can tolerate, which would limit the range of possible applications for these conductors. Second, it is probably preferred that the whole deformation processing to the final level of deformation true strain should be completed in the $\mathrm{Al} / \mathrm{Ca}$ composite state to prevent intermetallic transformation, so that all of the deformation above some significant level (maybe $\eta=5$ ) should be done at temperatures below about $150^{\circ} \mathrm{C}$.

Of course, this deformation level limit and the processing temperature boundary must both be investigated experimentally to determine them with more precision. Third, it may be preferred to fully transform the Ca filamentary phase to an intermetallic phase, probably $\mathrm{Al}_{2} \mathrm{Ca}$ after the completion of all desired deformation processing, to produce a conductor wire with the highest temperature stability and, effectively, to avoid having to place a limit on possible Joule heating from amperage overloads. This processing option also must be pursued in further work.

\section{Conclusions}

a) $\mathrm{An} \mathrm{Al} / \mathrm{Ca}(20 \mathrm{vol} . \%)$ nanofilamentary composite was produced by powder metallurgy and severe plastic deformation, utilizing gas atomized fine Al powders and centrifugally atomized fine Ca powders.

b) After deformation processing, most Ca filaments adopted a ribbon-shaped morphology instead of the cylindrical morphology expected for fcc metal reinforcement filaments.

c) The strength of the composite increased with deformation true strain due to the strong interfacial strengthening from finer Ca filaments, which can be described well by a HallPetch barrier model. 
d) An ultimate tensile strength of $476 \mathrm{MPa}$ was achieved for the Al-Ca metal-metal composite, which is superior to currently available commercial aluminum conductors.

e) The resistivity of the composite was slightly higher than the inverse-rule-of-mixtures prediction presumably due to crystal defects such as oxide debris inclusions and dislocations.

f) Both DSC continuous heating tests and resistivity measurements after elevated temperature annealing suggested that the $\mathrm{Al} / \mathrm{Ca}$ interfaces in the $\mathrm{DMMC}$ do transform to $\mathrm{Al}_{4} \mathrm{Ca}$ and, subsequently, to $\mathrm{Al}_{2} \mathrm{Ca}$ on heating.

g) The kinetics of initial $\mathrm{Al}_{4} \mathrm{Ca}$ formation and $\mathrm{Al}_{4} \mathrm{Ca}$ transformation into $\mathrm{Al}_{2} \mathrm{Ca}$ are greatly enhanced at elevated deformation true strain values.

\section{Acknowledgements}

The authors appreciate the financial support of ISU's Electric Power Research Center, Iowa State University Research Foundation, U.S. Department of Energy Office of Electricity, and Summit Technology Group LLC. The authors appreciate Qingfeng Xing for focused ion beam and some scanning electron microscopy work, at Ames Laboratory's Sensitive Instrument Facility; Ryan Ott and Matt Besser for use of their Zwick/Roell Z2.5 tensile system; Charles Spellman of Psylotech for tensile testing the high eta $\mathrm{Al} / \mathrm{Ca}$ specimens. The Ames Laboratory is operated for U.S. Department of Energy by Iowa State University contract no. DE-AC02-07CH11358

\section{References}

[1] L. Tian, I. Anderson, T. Riedemann, A. Russell, H. Kim, Prospects for novel deformation processed $\mathrm{Al} / \mathrm{Ca}$ composite conductors for overhead high voltage direct current (HVDC) power transmission, Electric Power Systems Research 105 (2013) 105-114.

[2] A.M. Russell, L.S. Chumbley, Y. Tian, Deformation processed metal - metal composites, Advanced Engineering Materials $2(1$ - 2) (2000) 11-22.

[3] J. Bevk, J.P. Harbison, J.L. Bell, Anomalous increase in strength of insitu formed $\mathrm{Cu}-\mathrm{Nb}$ multifilamentary composites, Journal of Applied Physics 49(12) (1978) 6031-6038. 
[4] L. Tian, I. Anderson, T. Riedemann, A. Russell, Modeling the electrical resistivity of deformation processed metal-metal composites, Acta Materialia 77 (2014) 151-161.

[5] A.M. Russell, I.E. Anderson, H.J. Kim, A.E. Freichs, Aluminum/alkaline earth metal composites and method for producing, Google Patents, 2014.

[6] L. Tian, H. Kim, I. Anderson, A. Russell, The microstructure-strength relationship in a deformation processed Al-Ca composite, Materials Science and Engineering: A 570 (2013) 106113.

[7] K. Xu, A.M. Russell, L.S. Chumbley, F.C. Laabs, V.B. Gantovnik, Y. Tian, Characterization of strength and microstructure in deformation processed Al-Mg composites, Journal of Materials Science 34(24) (1999) 5955-5959.

[8] A.M. Russell, T. Lund, L.S. Chumbley, F.A. Laabs, L.L. Keehner, J.L. Harringa, A highstrength, high-conductivity Al-Ti deformation processed metal metal matrix composite, Composites Part A: Applied Science and Manufacturing 30(3) (1999) 239-247.

[9] L. Tian, Structure-property relationships in an Al matrix Ca nanofilamentary composite conductor with potential application in high-voltage power transmission, IOWA STATE UNIVERSITY, 2015.

[10] J.R. Rieken, I.E. Anderson, M.J. Kramer, G.R. Odette, E. Stergar, E. Haney, Reactive gas atomization processing for Fe-based ODS alloys, Journal of Nuclear Materials 428(1-3) (2012) $65-75$.

[11] O.D. Neikov, I. Murashova, N.A. Yefimov, S. Naboychenko, Handbook of non-ferrous metal powders: technologies and applications, Elsevier2009.

[12] A.M. Russell, L.S. Chumbley, T.W. Ellis, F.C. Laabs, B. Norris, G.E. Donizetti, In situ strengthening of titanium with yttrium: texture analysis, Journal of Materials Science 30(17) (1995) 4249-4262.

[13] ASM-International, ASM Alloy Phase Diagram Database, Materials Park, OH, USA.

[14] C.A. Johnson, Generalization of the Gibbs-Thomson equation, Surface Science 3(5) (1965) 429-444.

[15] K. Ozturk, L.-Q. Chen, Z.-K. Liu, Thermodynamic assessment of the Al-Ca binary system using random solution and associate models, Journal of Alloys and Compounds 340(1-2) (2002) 199-206.

[16] C. Kittel, Introduction to solid state, John Wiley \& Sons, 1966. 
[17] D. Raabe, P.-P. Choi, Y. Li, A. Kostka, X. Sauvage, F. Lecouturier, K. Hono, R. Kirchheim, R. Pippan, D. Embury, Metallic composites processed via extreme deformation: Toward the limits of strength in bulk materials, MRS Bulletin 35(12) (2010) 982-991. 
(a)

(b)

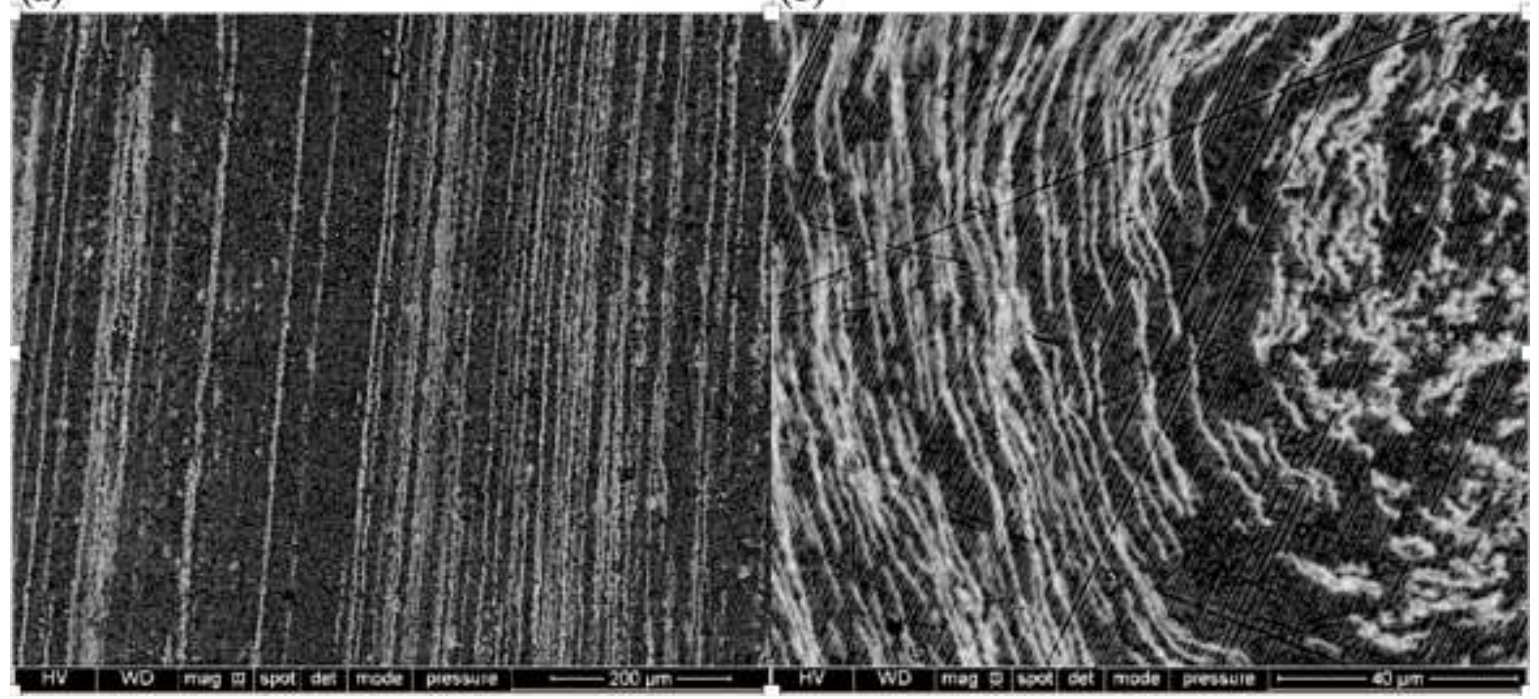

(c) ${ }^{\text {\% }}$

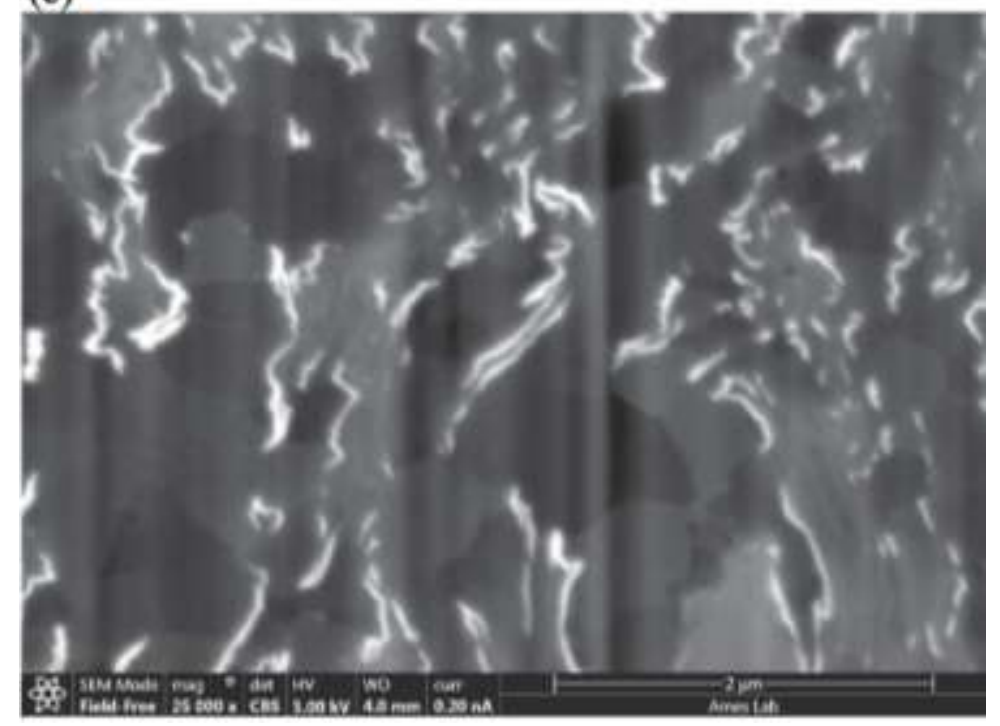

Figure 1. Back-scattered electron SEM (scanning electron microscopy) micrographs of $\mathrm{Al}-\mathrm{Ca}$ (20 vol.\%) composite: (a) longitudinal cross section at deformation true strain $\eta 6.38$, (b) transverse cross section at $\eta 8.52$, (c) transverse cross section at $\eta 12.91$. The light-gray phase is $\mathrm{Ca}$; the dark-gray phase is Al. Grain structure contrast is visible within the Al in (c). The vertical bands in this micrograph are "curtaining" artifacts from the focused-ion beam cutting. 

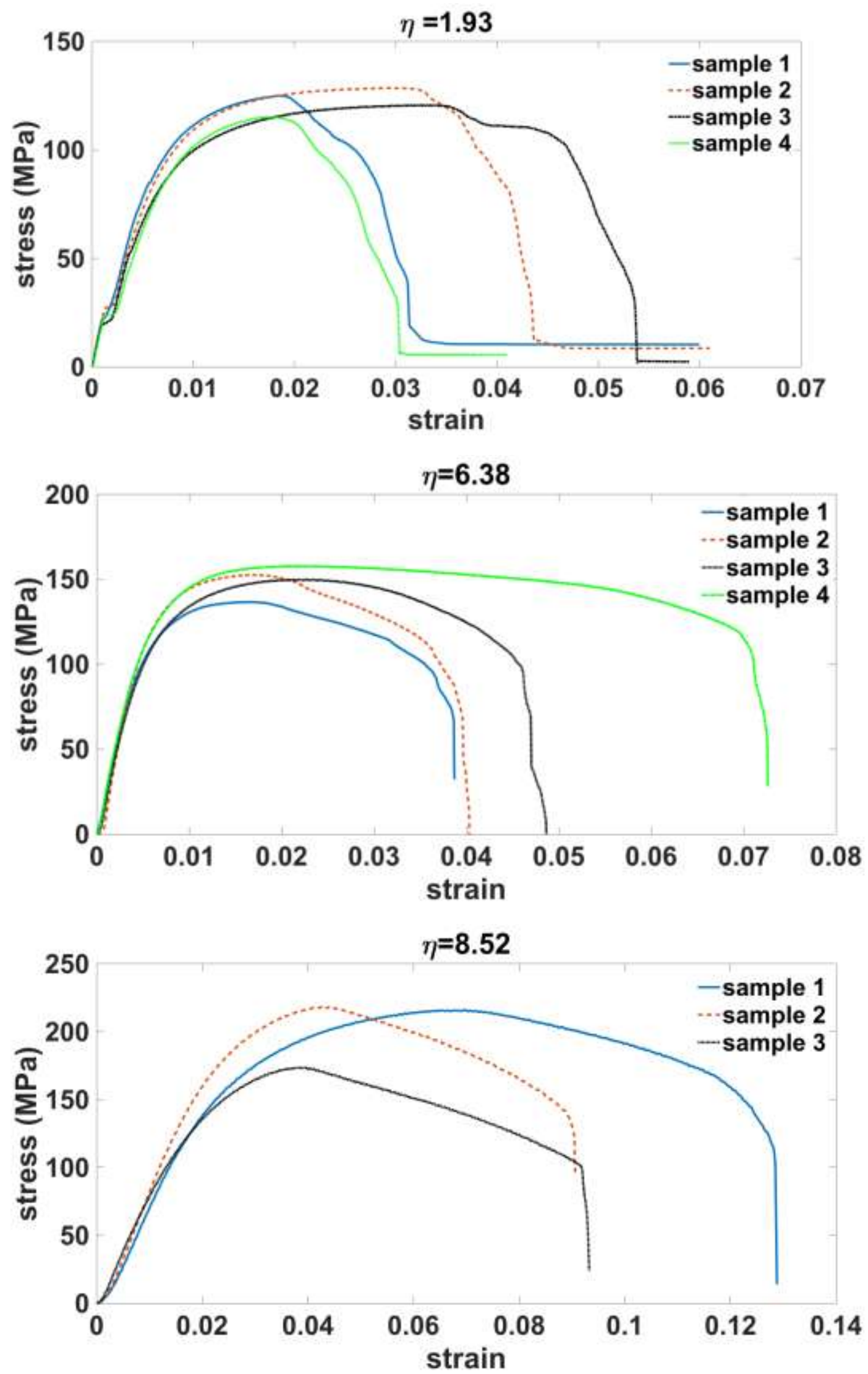

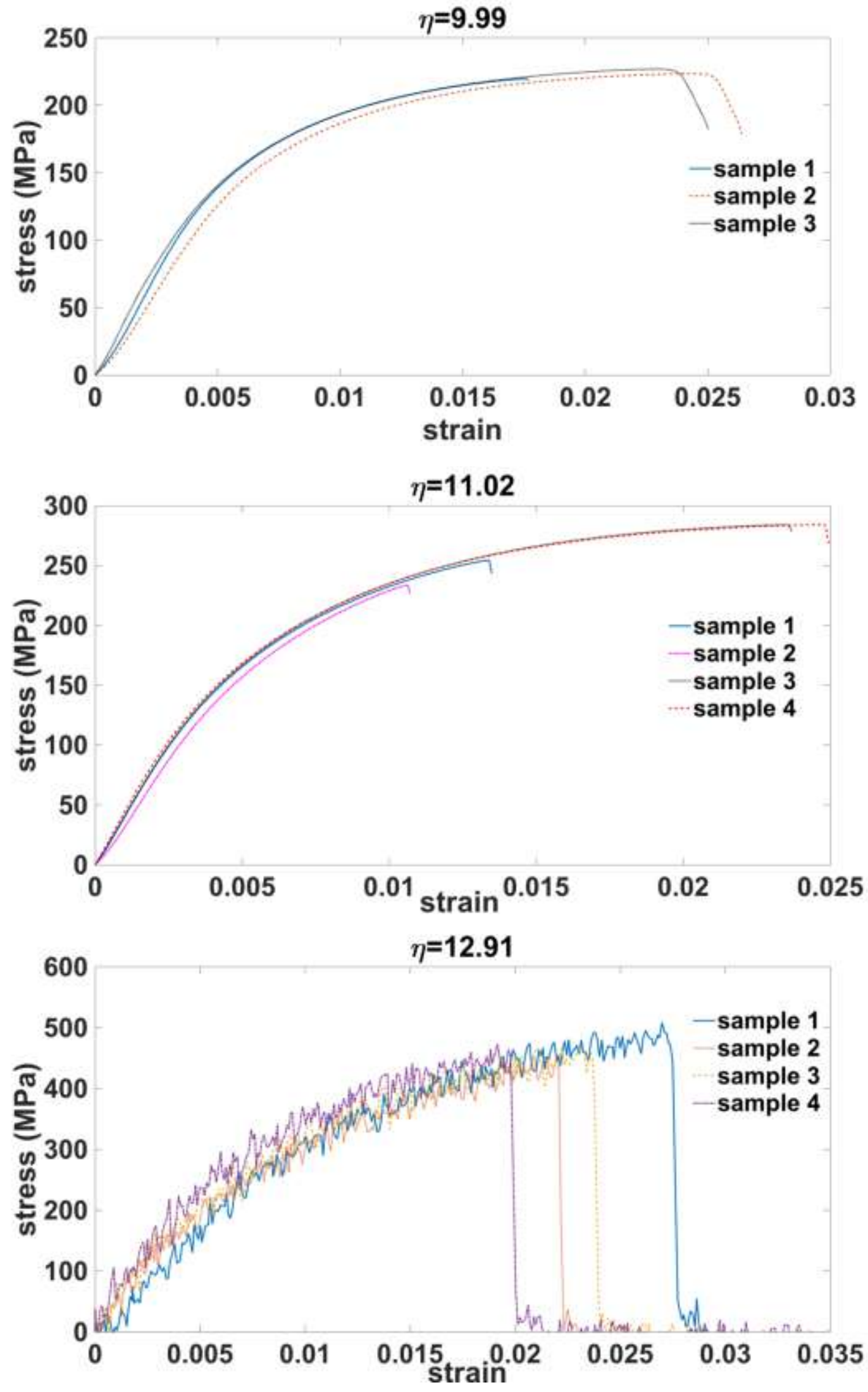
Figure 2. Tensile tests of $\mathrm{Al} / \mathrm{Ca}(20 \mathrm{vol} . \%)$ composite at various deformation true strain levels.

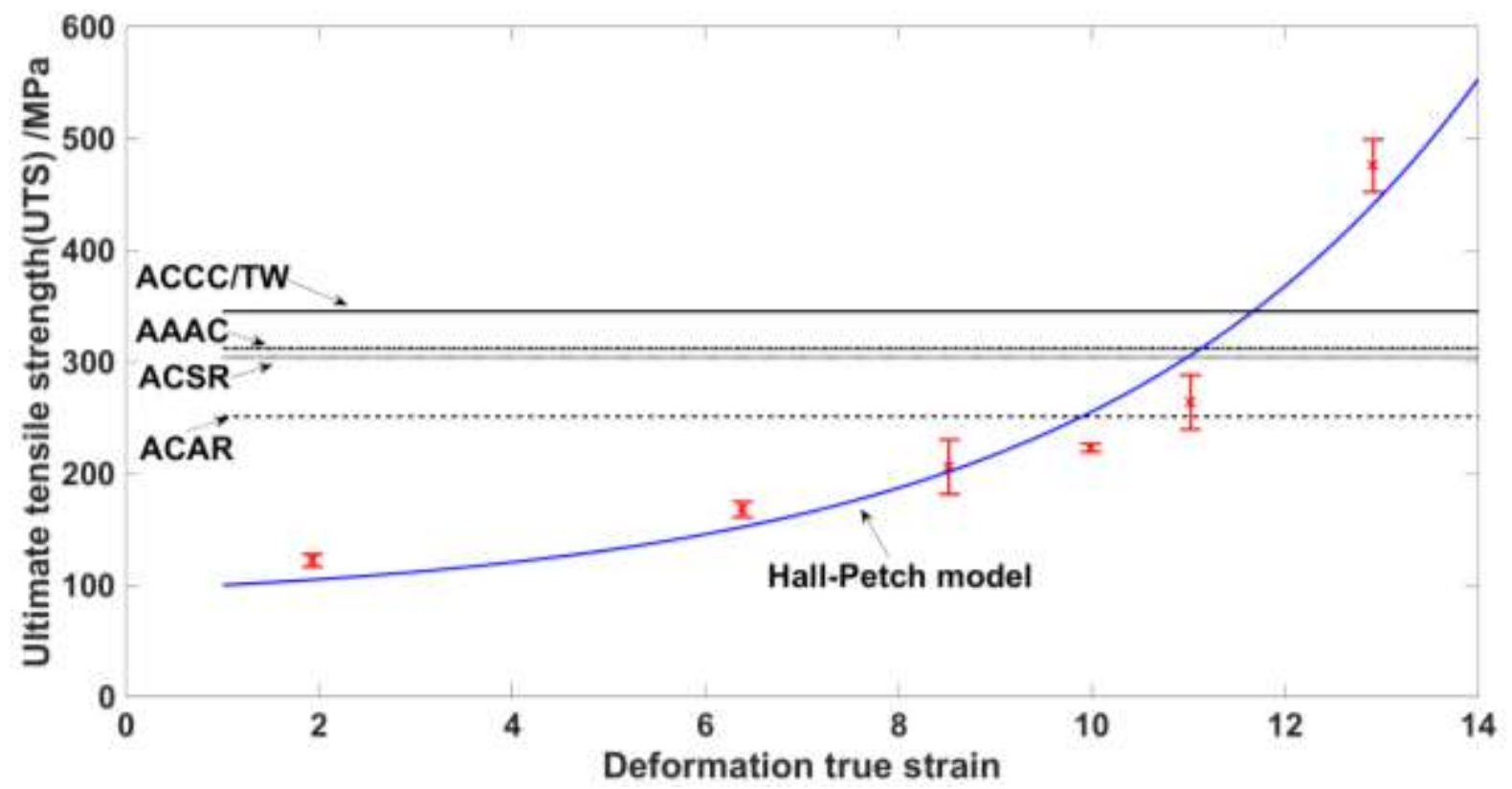

Figure 3. Tensile strength of Al-20 vol.\%Ca composite as a function of deformation true strain. The experimental data are fitted by a Hall-Petch barrier model, which is the solid curve. The ultimate strengths of four commonly used commercial conductors are shown for comparison. (ACAR=Aluminum Conductor Aluminum Alloy Reinforced; ACSR=Aluminum Conductor Steel Reinforced; AAAC=All Aluminum Alloy Conductor; $\mathrm{ACCC} / \mathrm{TW}=$ Aluminum Conductor Composite Core with Trapezoidal Wire cross section.)

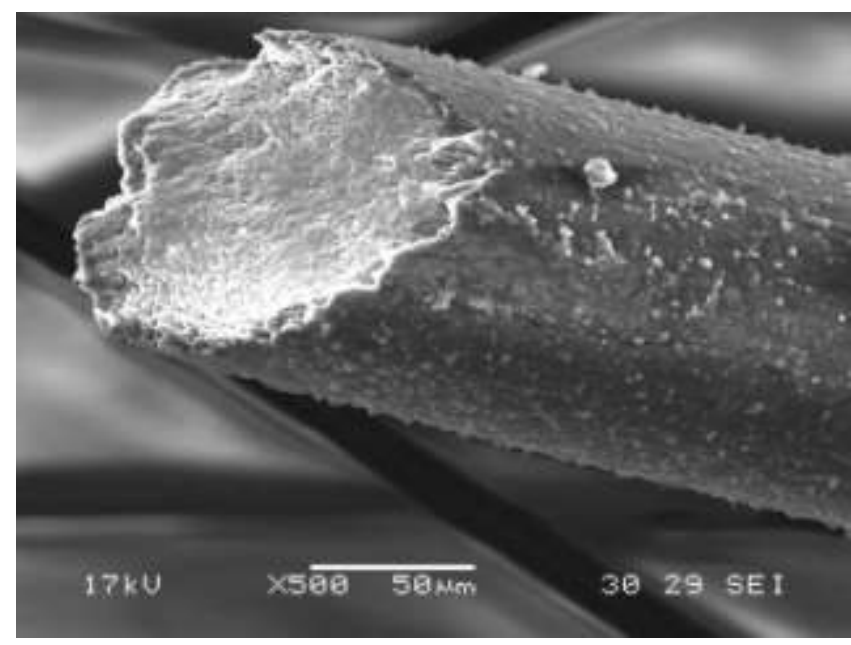

Figure 4. The fracture surface of tensile tested sample at deformation true strain of 12.9. 

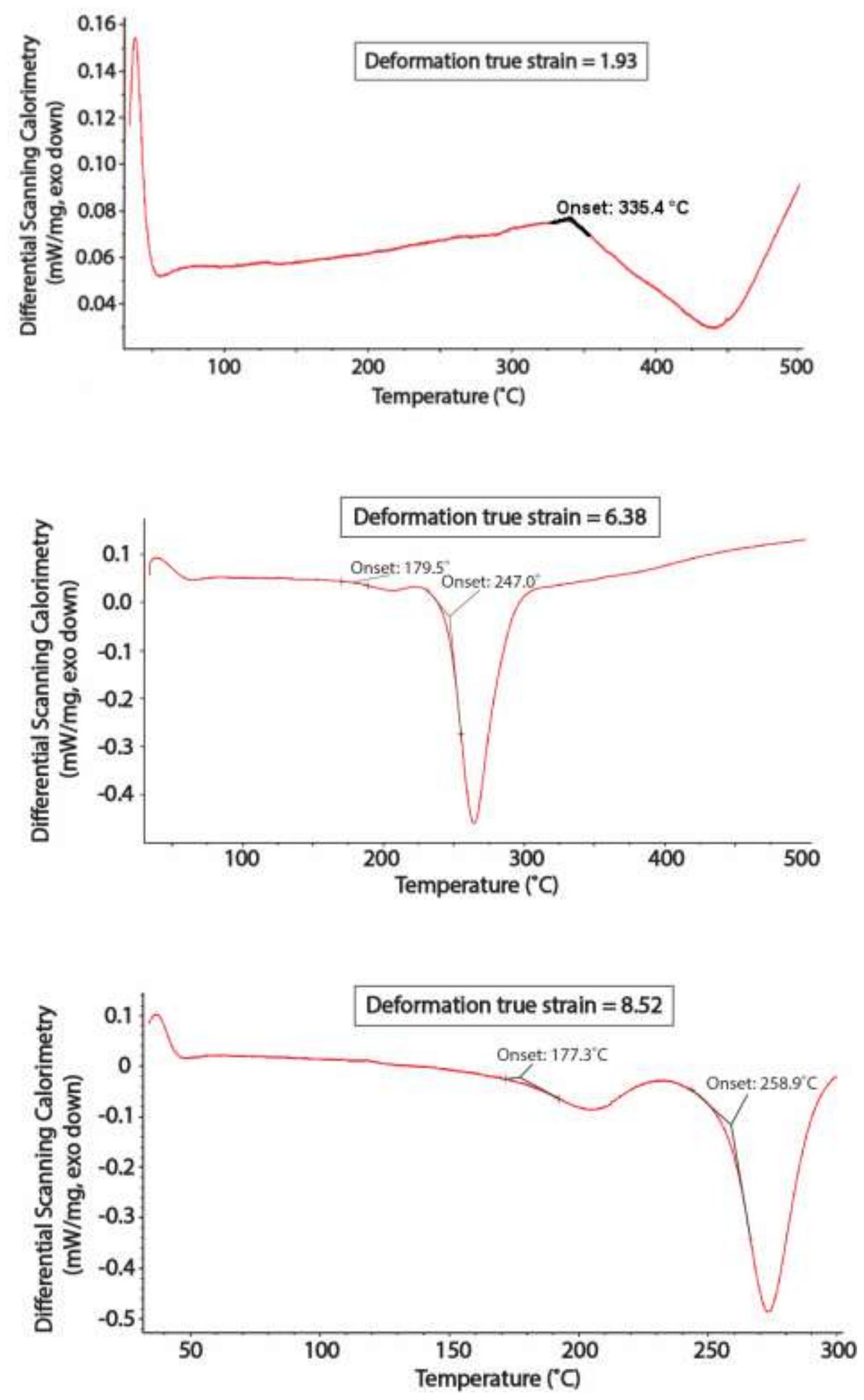
Figure 5. The DSC curves for $\mathrm{Al} / \mathrm{Ca}$ (20 vol. \%) composite samples at different deformation true strains under argon atmosphere. The as-extruded $27.3 \mathrm{~mm}$ sample has deformation true strain of 1.93. The as-swaged $3 \mathrm{~mm}$ sample has deformation true strain 6.38 . The as-swaged $1 \mathrm{~mm}$ sample has deformation true strain 8.52.

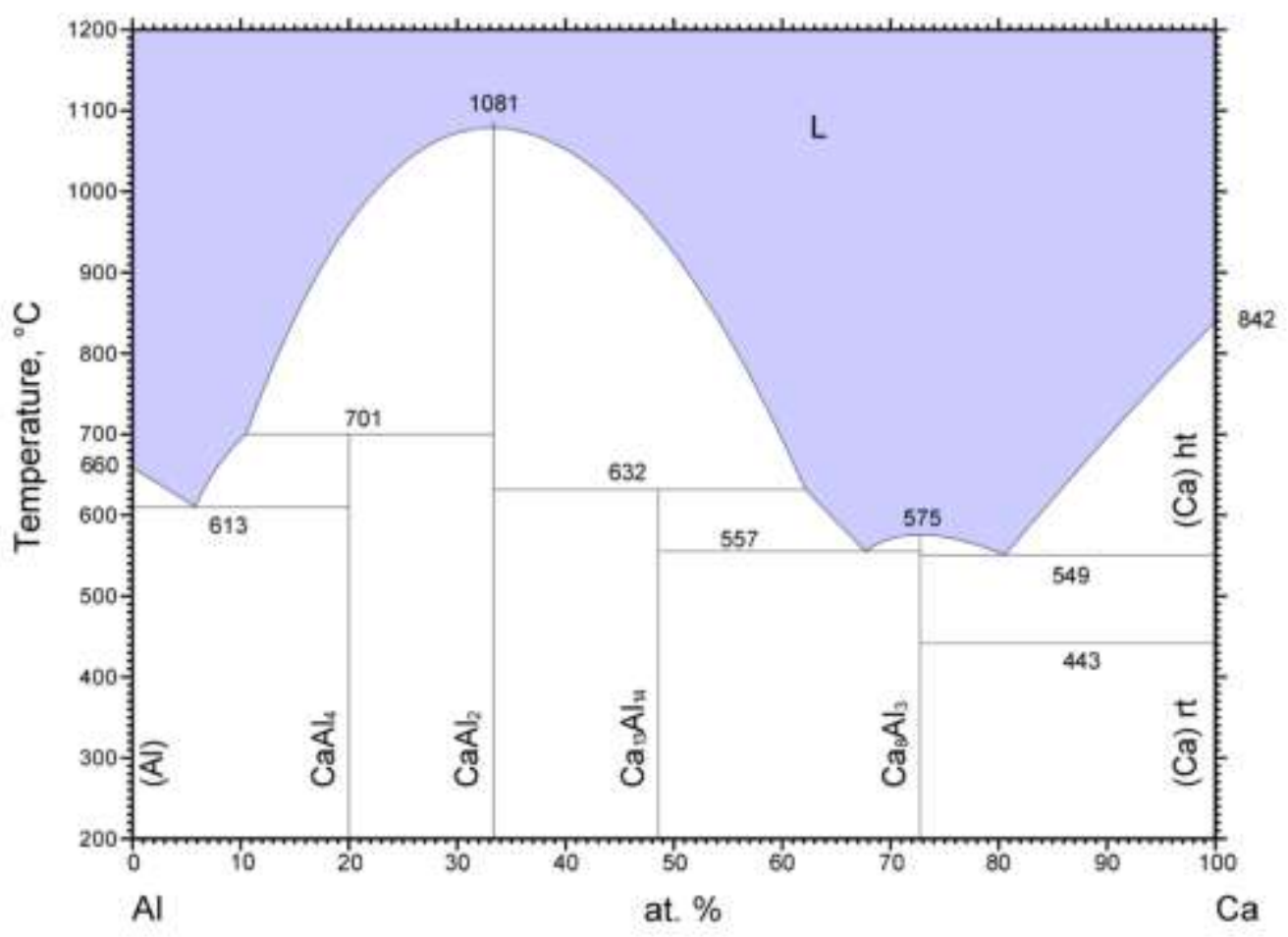

Figure 6. Phase diagram for the Al-Ca system. ASM Diagram No. 1600365, Okamoto (2003) [13]. 


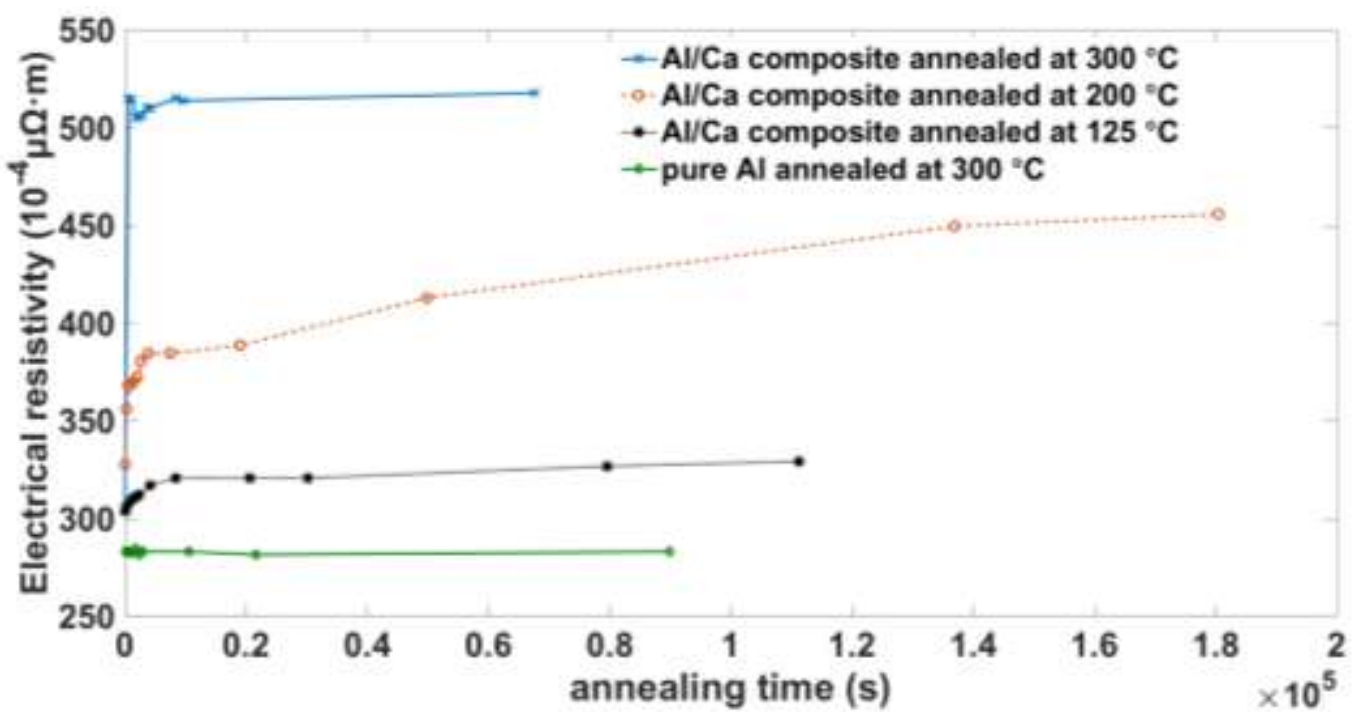

Figure.7 Summary of the electrical resistivities of $1 \mathrm{~mm}$ dia. $\mathrm{Al} / \mathrm{Ca}(20 \mathrm{vol} . \%)$ composite wire as a function of annealing time at $300^{\circ} \mathrm{C}, 200^{\circ} \mathrm{C}$, and $125^{\circ} \mathrm{C}$ (data from Tables 3,5 , and 6 respectively), along with electrical resistivity data from $1 \mathrm{~mm}$ dia. pure Al wire (data from Table 4) annealed at $300^{\circ} \mathrm{C}$. 
Table 1. Calcium filament thicknesses at different deformation true strains measured from the SEM micrographs in Fig. 1.

\begin{tabular}{|l|l|}
\hline Deformation true strain $\eta$ & Ca filament thickness $(\mu \mathrm{m})$ \\
\hline 6.38 & 4.97 \\
\hline 8.52 & 1.76 \\
\hline 12.91 & 0.05 \\
\hline
\end{tabular}

Table 2. The ultimate tensile strength of $\mathrm{Al} / \mathrm{Ca}$ (20 vol.\%) composites at various deformation true strains.

\begin{tabular}{|c|c|}
\hline Deformation True Strain & Ultimate Tensile Strength (MPa) \\
\hline 1.93 & 122 \\
\hline 6.38 & 168 \\
\hline 8.52 & 206 \\
\hline 9.987 & 223 \\
\hline 11.02 & 264 \\
\hline 12.91 & 476 \\
\hline
\end{tabular}

Table 3. The electrical resistivities of $1 \mathrm{~mm} \mathrm{Al} / \mathrm{Ca}(20$ vol. \%) composite wire (deformation true strain 8.5) annealed at $300^{\circ} \mathrm{C}$ for different times.

\begin{tabular}{|l|l|l|l|l|l|l|l|l|l|l|l|}
\hline Annealing time (s) & 0 & 600 & 1200 & 1800 & 2400 & 3000 & 3600 & 4200 & 8400 & 9600 & 67680 \\
\hline $\begin{array}{l}\text { Electrical resistivity } \\
\left(10^{-4} \mu \Omega \cdot \mathrm{m}\right)\end{array}$ & 305 & 515 & 515 & 505 & 505 & 507 & 510 & 510 & 515 & 514 & 518 \\
\hline
\end{tabular}

Table 4. The electrical resistivities of $1 \mathrm{~mm}$ pure $\mathrm{Al}$ wire (deformation true strain 8.5 ) annealed at $300^{\circ} \mathrm{C}$ for different times.

\begin{tabular}{|l|l|l|l|l|l|l|l|l|l|}
\hline Annealing time (s) & 0 & 600 & 1200 & 1800 & 2400 & 3000 & 10500 & 21600 & 90000 \\
\hline Electrical resistivity $\left(10^{-4} \mu \Omega \cdot \mathrm{m}\right)$ & & & & & & & & & \\
\hline
\end{tabular}

Table 5. The electrical resistivities of $1 \mathrm{~mm} \mathrm{Al} / \mathrm{Ca}(20$ vol. \%) composite wire (deformation true strain 8.5) annealed at $200{ }^{\circ} \mathrm{C}$ for different times. 


\begin{tabular}{|l|l|l|l|l|l|l|l|l|l|l|l|l|l|}
\hline $\begin{array}{l}\text { Annealing } \\
\text { time (s) }\end{array}$ & 0 & 300 & 600 & 900 & 1500 & 2100 & 2700 & 3900 & 7560 & 18960 & 49860 & 136920 & 180540 \\
\hline $\begin{array}{l}\text { Electrical } \\
\text { resistivity }\left(10^{-}\right. \\
\left.{ }_{\mu} \mu \cdot \mathrm{m}\right)\end{array}$ & 328 & 356 & 368 & 368 & 370 & 372 & 380 & 384 & 384 & 389 & 413 & 450 & 456 \\
\hline
\end{tabular}

Table 6. The electrical resistivities of $1 \mathrm{~mm} \mathrm{Al} / \mathrm{Ca}$ (20 vol. \%) composite wire (deformation true strain 8.5) annealed at $125^{\circ} \mathrm{C}$ for different times.

\begin{tabular}{|l|l|l|l|l|l|l|l|l|l|l|l|}
\hline $\begin{array}{l}\text { Annealing } \\
\text { time (s) }\end{array}$ & 0 & 600 & 1200 & 1800 & 2400 & 4200 & 8400 & 20580 & 30180 & 79560 & 111240 \\
\hline $\begin{array}{l}\text { Electrical } \\
\text { resistivity } \\
\left(10^{-4} \mu \Omega \cdot \mathrm{m}\right)\end{array}$ & 304 & 307 & 310 & 311 & 312 & 317 & 321 & 321 & 321 & 327 & 329 \\
\hline
\end{tabular}

